\title{
Combined Therapy for Paclitaxel and Curcumin by Nonionic Surfactant Vesicles Leading to Enhanced Efficacy of Chemotherapy in Ovarian Cancer Cells Through Inhibiting the Serine/threonine Kinase Akt and Nuclear Factor Kappab Activity
}

ashraf alemi ( $\sim$ alemi.ashraf@gmail.com )

Abadan University of Medical Sciences https://orcid.org/0000-0003-1780-7540

Mojtaba Haghi Karamallah

Ahvaz Jundishapur University of Medical Sciences: Ahvaz Jondishapour University of Medical Sciences

Seyed Ahmad Hosseini

Ahvaz Jundishapur University of Medical Sciences: Ahvaz Jondishapour University of Medical Sciences

Noorollah Tahery

Abadan University of Medical Sciences

Esmat Radmanesh

Abadan University of Medical Sciences

Reza Malihi

Abadan University of Medical Sciences

Majid Farrokhifar

Sabzevar University of Medical Sciences

Saeed Farokhifar

Islamic Azad University of Shahrood

Somayeh Haghi Karamallah

Shiraz University of Medical Sciences

Hadi Zare-Zardini

Shahid Sadoughi University of Medical Sciences and Health Services

Mohammad Farokhifar

Kar Higher Education Institute

Research

Keywords: Paclitaxel, Curcumin, Nonionic Surfactant Vesicles, AKT-1 gene, NF-KB activity, OVCAR-3 cell

Posted Date: August 11th, 2021 
DOl: https://doi.org/10.21203/rs.3.rs-783542/v1

License: (c) (1) This work is licensed under a Creative Commons Attribution 4.0 International License. Read Full License 


\section{Abstract}

The combination therapy of cytotoxic drugs and chemosensitizing agents encapsulated in nanoparticles has been highlighted as an effective treatment for various cancers. Combination therapy is promising to produce synergistic anticancer effects, to magnify the treatment effect and overcome multidrug resistance. In this investigation, we have studied augmentation of therapeutic efficacy upon c combinational treatment of paclitaxel (PCL) and curcumin (Cur), an inhibitor of nuclear factor kappa B (NF-KB), in OVCAR-3 cell. PCL and Cur were encapsulated in nanoniosome formulations. Then, the effects of nanoniosome formulations on cytotoxicity, expression profile of $A K T-1$ gene and NF-KB activity were evaluated. The findings showed that nanoniosomes were highly efficient in delivering the PCL and Cur drugs to OVCAR-3 cell. A 3-fold and 3.6-fold reduction in Cur and PCL concentration were measured, respectively, when the Cur and PCL were administered in nanoniosomes compared to free Cur and free PCL solutions in OVCAR-3 cell. Moreover, curcumin could significantly increase cell growth inhibition of paclitaxel so that, in presence of NioCur, the $\mathrm{IC}_{50}$ of NioPCL was diminished to $\sim 2.4-$ fold. AKT-1 gene expression studies showed that co-administration of curcumin/paclitaxel nanoniosome formulations caused $91.2 \%$ reduction in $A K T-1$ gene expression compared to control group. On the other hand, this coadministration caused $79.42 \%$ reduction in the amount of NF-KB activity and a 4 -fold reduction in the activity of the MDR protein pumps in cancer cells compared to the control group. Our findings demonstrate that the combination therapy of PCL with Cur using the nanoniosomes delivery is a promising strategy for breast cancer more effective therapy

\section{Introduction}

There are some limitations for systematically administering single-drug chemotherapy, such as fast blood/renal clearance, multiple drug resistance, or poor bioavailability. Additionally, the drug is frequently at low levels at the tumor sites; thus, an effective drug dose cannot be reached. Consequently, higher doses of drug are required within administration, resulting in severe negative side effects (1-3). Combined chemotherapy for cancer treatment has been recently proposed that is a promising approach for generating synergistic antitumor impacts, reducing individual drug-associated toxicity, suppressing multiple drug resistance (MDR) through different action mechanisms, and reducing the required dosage of each drug. In combined chemotherapy, two or more active drugs are simultaneously administered for inducing cell cycle arrest in a different stage of the cell cycle, for modulating various signaling pathways in cancerous cells, for maximizing the therapeutic impact, and overcoming MDR. Combined treatment utilizes a pharmacologically safe and natural anticancer drug along with a very robust toxic commercial anticancer agent, which make it an attractive strategy for obviating these constraint. Toxicity in natural anticancer drug is significantly lower, it is easily available and safe (4-7). An example for these agents is Curcumin (Cur) (8). Cur (Diferuloylmethane) is a natural diphenol compound, purifying from the plant rhizome, Curcuma longa (which is a member of the ginger family) (9). Cur is popular for its antiinflammatory, anti-amyloid, antibacterial and antioxidant properties, and anti-spasmodic activity. Moreover, it has also be reported as an anticancer agent with the ability of suppressing and treating 
different types of malignancies. Cur also can indicate p-gp inhibitory activity independently by downregulating the NF-kB and PI3K/Akt pathways. Additionally, Paclitaxel (PCL) is a very powerful and anticancer, which is obtained from the dark of the Pacific yew tree, Taxus brevifolia. It is used for treating different types of cancers, like breast, lung, esophageal, and ovarian cancers. The PCL has an anticancer mechanism that blocks mitosis, resulting in arresting $\mathrm{G} 2 / \mathrm{M}$ cell cycle and apoptosis cell death $(7,10)$. It has commonly been studied combined with other chemotherapeutic drugs for enhancing and increasing its therapeutic efficacy and reducing its toxicity. It is an attractive anticancer strategy to combine PCL and Cur. PCL is known as a potent microtubule-stabilizing drug, which causes cell cycle arrest, while Cur presents a biological attack through regulation of various signal transduction pathways (8). Although there are good therapeutic impacts, Cur and PCL have poor solubility in water. Hence, because of demands for effective PCL and Cur delivery approaches, attractive systems have been developed for PLC and Cur formulations, like polymeric micelles, polymeric NPs, liposomes, nanogels, niosomes, cyclodextrin, and biodegradable microspheres (11-14). Niosome is a non-ionic vesicle that is based on surfactant and developed by non-ionic surfactant and cholesterol incorporation as an excipient. Also, other excipients can be employed. Liposome-related drawbacks can be reduced by niosomes, which include chemical instability because of their tendency to oxidative degradation and varying purities of phospholipids .As drug carriers, niosomes present considerable advantages making them superior over other common vesicular delivery approaches. The main factors inspiring development of niosomal systems include chemical stability, biocompatibility, biodegradability, easy handling and storage, low toxicity, and low production cost (15-18). In the present work, the combined delivery of Cur and PCL, compressed in PEGylated niosomal formulations, is examined for augmenting their efficacy in OVCAR-3 human ovarian cancer cell. NF-KB pathway inhibition and Akt-1 gene down-expression were also investigated after single treatment and combined treatment in aqueous solution and nanoniosomal formulations.

\section{Materials And Methods}

\subsection{Preparation of Cur/ PCL - loaded niosomes}

The Cur/ PCL -loaded niosomes were developed using thin film hydration approach (19). We dissolved cholesterol (Sigma-Aldrich, USA), polyethylene glycol (Lipoid GmbH, Germany), and Tween 60 (SigmaAldrich, USA) (64.4: 27.6: 5 molar ratios) in chloroform. It was followed by dissolving Cur (Sigma-Aldrich, USA) and PCL (Stragen, Switzerland) in methanol, and it was mixed with the mix of lipids and surfactant. Fluorescent label DIL (Sigma, USA) was mixed with lipid phase at $0.1 \% \mathrm{~mol}$ for evaluating the cellular

uptake. A dose of $0.5 \mathrm{mg} \cdot \mathrm{mL}^{-1}$ was used for both drugs. Phosphate- Buffered Saline (PBS, $\mathrm{pH}=7.4$ ) was used for hydrating dry lipid film by rotary device (Heidolph, Germany). Then, we sonicated the vesicles were for decreasing the vesicles mean size. Afterward, free PCL and Cur (unloaded) were eliminated from niosomal PCL and Cur (NioPCL and NioCur) by a dialysis bag diffusion approach against PBS. It was accomplished at $4^{\circ} \mathrm{C}$ for $1 \mathrm{~h}(\mathrm{MW}=8-14 \mathrm{kDa})$. The dynamic light scattering (DLS) method was used for evaluating zeta potential and polydispersity index of Cur/ PCL -loaded niosomes and the particle size 
distribution by Brookhaven Corp Instruments (Holtsville, NY). Spectroscopic measurements were performed at $236 \mathrm{~nm}$ and $429 \mathrm{~nm}$ ( $\lambda$ max of drugs) for evaluating the entrapment efficiency of PCL and Cur in niosomal formulations. The dialysis of $1 \mathrm{~mL}$ of the niosome preparations was performed for assessing Niosomal Cur/PCL release. For this purpose, an 8- 14-kDa cutoff dialysis tube was used in PBS $\mathrm{pH} 7.4$ at $37^{\circ} \mathrm{C}$ under constant stirring. Spectrophotometry was used for detecting the release amount of Cur/PCL into vesicle at pre-specified time intervals by considering $1 \mathrm{~mL}$ of the dialysis medium and its replacement with the same volume of fresh PBS (20-23).

\subsection{Cytotoxicity assays}

The MTT (Sigma, USA) assay was used for calculating the $\mathrm{IC}_{50}$ values of Cur and PCL as single drugs or as combined treatment. In short, we seeded OVCAR-3 cell in 96 -well plates at $1 \times 10^{4}$ cells per well. After 24 $\mathrm{h}$, treatment of the cells with $200 \mu \mathrm{l}$ fresh medium was done that contained serial dilutions of the various niosomes/ drugs formulations. The product was incubated for $48 \mathrm{~h}$, and then, $20 \mu \mathrm{l}$ MTT was mixed with well plates, followed by incubation at $37^{\circ} \mathrm{C}$ for $3 \mathrm{~h}$. Lastly, we added $180 \mu \mathrm{l}$ of DMSO to the wells for dissolving the formed formazan crystals. EPOCH Microplate Spectrophotometer (BioTek, USA) was used for recording absorbance of the wells at $570 \mathrm{~nm}$. GraphPad Prism 6 was used for calculating the $\mathrm{IC}_{50}$ values of Cur and PCL as single drugs or as combined treatment. The Combination Index $(\mathrm{Cl})$ value was calculated for appraising combined Cur and PCL. This index was obtained by Talalay and Chou Eq. and the CompuSyn software (20-22, 24-27).

\subsection{Nanocarrier Uptake Surveys}

Seeded OVCAR-3 cell in 6-well plates at a cell density of $1 \times 10^{4}$ cells/well were used for investigating the in-vitro cellular uptake of the Cur/ PCL-loaded niosomes. Cell growth was performed overnight so that $80 \%$ confluence is reached. Afterward, treatment with DIL-labeled PCL Niosome (DIL-NioPCL) and DILlabeled Cur Niosome (DIL-NioCur) was done, and then incubation was done at $37^{\circ} \mathrm{C}$ for three hours. OVCAR-3 cell wase then rinsed with PBS three times, and they were fixed with $4 \%$, paraformaldehyde solution (Sigma, USA). Lastly, the cell incubation was performed with DAPI solution for $15 \mathrm{~min}$, and a fluorescence microscope was employed for imaging the cells $(20,24,28)$.

\subsection{Evaluation of Annexin V-Fluorescein Isothiocyanate (FITC)/propidium iodide (PI)}

Propidium iodide (PI) and Annexin V-FITC staining were used for determining apoptosis. We then seeded OVCAR-3 cells at a density of 100000 cell/well for 24 hours prior to experiment in 6-well plates. Afterward, cell treatment with PCL and Cur was performed, either as combined PCL + Cur or as single drugs. The drugs were administered in nano-niosome formulations or in aqueous solution. Following incubating for $24 \mathrm{~h}$, cold PBS was used for trypsinizing and washing the cells. The PI and Annexin V-FITC were used for staining cells for $30 \mathrm{~min}$. BD FACSCalibur instrument was employed for analyzing cells. Plots were classified into quadrants for assessing the percentages of apoptotic cells and living cells. FlowJo 
software (FlowJo LLC, Ashland, OR, USA) was employed for data analysis. The control group included cells not receiving any drug treatment (29-31).

\subsection{Real-time PCR analysis}

real-time PCR analysis was performed for investigating the synergistic impacts of Cur and PCL on expression of Akt-1 gene. We seeded OVCAR-3 cell in 6-well plates at $1 \times 10^{6}$ cells in each well. After $24 \mathrm{~h}$, the cell treatment with fresh medium was conducted. The medium contained the various niosomes/drugs formulations: free-Cur solution, free-PCL solution, free-PCL + free Cur physical mix, niosomal PCL, niosomal Cur, and co-administered niosomal PCL + niosomal Cur. The control group included cells not receiving any drug treatment. Following a 48-hour incubation, Super RNA extraction Kit (yekta tajhiz, Iran) was used for extraction of total RNA. RevertAid First Strand cDNA Synthesis Kit (Thermo Scientific,USA) was used for performing the RNA reverse transcription in accordance with the instructions of the manufacturer. We used CDNA as a template for subsequent qPCR amplification by primers specific for Glycer Aldehyde 3-Phosphate Dehydrogenase (GAPDH) and Akt-1 genes. These primers were used for qPCR: forward 5'- CTTCTATGGCGCTGAGATTGTG -3', reverse 5'- CAGCATGAGGTTCTCCAGCTT-3'; Akt-1, GAPDH, forward 5'- GCAAGAGCACAAGAGGAAGA -3' and reverse 5'- ACTGTGAGGAGGGGAGATTC -3'. The qPCR reaction contained a primary activation phase for 5 minutes at $94^{\circ} \mathrm{C}$, followed by 35 cycles for $30 \mathrm{~s}$ at $94^{\circ} \mathrm{C}$, annealing for $30 \mathrm{~s}$ at $60^{\circ} \mathrm{C}$, extension for $30 \mathrm{~s}$ at $72^{\circ} \mathrm{C}$, and a final extension for $7 \mathrm{~min}$ at $72^{\circ} \mathrm{C}$. Rotor-Gene Q Real-Time PCR System (qiagen, USA) and 5x HOT FIREPol $®$ EvaGreen $\circledast$ qPCR Mix Plus the real-time PCR kit (Solis BioDyne, Estonia) were used for performing qPCR. Rotor-Gene Q Real-Time PCR System Software provided raw data, which was exported in rdml format and imported to LinRegPCR for calculating the PCR efficiency. In each experiment, $\mathrm{Ct}$ values were obtained that were employed an indicator for gaining fold change in the target genes' expression normalized to GAPDH. $2^{-\triangle \Delta C t}$ technique was used for calculating the relative expression levels regarding fold change by Gene software (MultiD Analyses AB, Sweden) (32-35).

\subsection{Determining p65-NF-kB by ELISA assay}

The DNA binding activity of NF-KB was examined by ELISA for investigating the synergistic impacts of Cur and PCL on p65-NF-KB activity. Abcam (Cambridge, United Kingdom) prepared the NF-kB p65 transcription factor assay kit (catalog no. ab133112). We seeded OVCAR-3 cells in 75-cm2 tissue culture flask. After $24 \mathrm{~h}$, the cell treatment with fresh medium was performed. The medium contained various niosomes/drugs formulations: free-Cur solution, free-PCL solution, free-PCL + free Cur physical mix, niosomal PCL, niosomal Cur, and co-administered administered niosomal PCL + niosomal Cur. Control group contained cells not receiving any drug treatment. Following a 48-h incubation, a nuclear extraction kit (ab113474, Abcam) was used for obtaining nuclear extracts based on the manufacturer's protocol. A sensitive ELISA assay was used for determining levels of nuclear p65 concentrations. Shortly, a certain double stranded DNA (dsDNA) sequence with the p65-NF-kB response element was immobilized onto the well bottoms on a 96-well plate. p65-NF-kB included in a nuclear extract attached to the p65-NF-kB response elements. Specific primary antibody directed against p65-NF-KB was added to detect p65-NF- 
KB. It was followed by addition of a secondary antibody conjugated to HRP, and spectrophotometer was used for reading the absorbance at $450 \mathrm{~nm}(36-38)$.

\subsection{Statistical analysis}

GraphPad Prism 6 software was utilized to analyze statistical data, and data were presented as mean \pm SD. For comparison of two independent groups, the student t-test was employed. Multiple samples were compared by the ANOVA test. P-Values smaller than 0.05 were regarded significant.

\section{Results}

\subsection{Characterization of Cur / PCL loaded nanoniosomes}

The mean size, $\mathrm{PDI}$, zeta potential, and encapsulation efficiency of the formulation of Curcumin-loaded nano-niosome were $88.7 \pm 1.7 \mathrm{~nm}, 0.148 \pm 0.011,-19.08 \pm 2.46$ and $97.22 \% \pm 2.4$. The mean size, PDI, zeta potential and encapsulation efficiency of the formulation of paclitaxel -loaded nano-niosome were $97.8 \pm 1.3 \mathrm{~nm}, 0.153 \pm 0.012,-17.92 \pm 0.15$ and $96.41 \% \pm 1.7$.

In vitro assessment of the drug release was conducted by dialysis technique. The profile of PCL and Cur release from niosomal formulations at $37^{\circ} \mathrm{C}$ is indicated in Fig. 1. After $72 \mathrm{~h}, 33.39$ was released for Cur and $30.28 \%$ was released for PCL of the loaded drugs (Fig. 1). The PCL and Cur showed a biphasic release profile with a fast primary release. A slower release phase was then appeared.

Figure 1 The in vitro release profile of curcumin and paclitaxel from niosome formula.

\subsection{Cytotoxicity assays}

MTT assay was used for specifying the inhibitory impact of individual Cur and PCL as drug niosomal form on OVCAR-3 cell and a free form. Figure 2 indicates that independent therapies with the nanoniosomal form and the free form led to inhibited growth of OVCAR-3 cell in a dose-dependent manner. In Table 1 , the $\mathrm{IC}_{50}$ values of the mentioned agents are evaluated. Figure $2 \mathrm{~b}$ demonstrates higher efficiency of nanoniosomes in transporting PCL and Cur drugs to OVCAR-3 cell. With administrating PCL and Cur in nanoniosomes, PCL and Cur concentration was reduced by 3.8 -fold and 2.8 fold reduction in Cur and PCL concentration in comparison with free PCL and free Cur and solutions in OVCAR-3 (Table 1). Then, we used the $\mathrm{IC}_{50}$ concentrations for generating fixed ratios for the next combination experiments and calculating combination index $(\mathrm{Cl})$. A combination study was carried out for determining the synergistic antitumor impacts of PCL and Cur, results of which are given in Table 2. The dose-response curves for OVCAR-3 cell exposed to combined treatment with PCL and Cur are shown in Fig. 3a, b. Combined treatment with PCL and Cur decreased cell viability more in OVCAR-3 than either PCL or Cur alone. When delivering PCL and Cur in nanoniosome formulations, such combined treatment has a significantly efficacy ( $p$-value $<0.05$ ) in comparison with a free solution (Table 2). Therefore, the concurrent usage of PCL and Cur led to enhancement of therapeutic potential. Also, the $\mathrm{Cl}$ analysis of the Cur and PCL interaction in OVCAR-3 cell is illustrated in Fig. 3c, d. The PCL and Cur combination in 
niosomal forms and free forms showed values of $\mathrm{Cl}<1$, which demonstrates synergistic interaction of the two drugs for cell growth inhibition (Table 2, Fig. 3c,d).

Table 1

The $\mathrm{IC}_{50}$ values of Cur and PCL alone and in combined form on OVCAR-3 cell, administered in the free drug forms and drug niosomal form. Data is expressed as the mean \pm SD

\begin{tabular}{|ll|}
\hline Treatment type & IC $_{50}$ values \\
\hline Free Curcumin Solution & $50.12 \pm 1.76$ \\
\hline Free Paclitaxel Solution & $18.56 \pm 0.65$ \\
\hline Free Paclitaxel + Free Curcumin Solution & $13.25 \pm 1.22$ \\
\hline Curcumin Niosome & $17.94 \pm 2.81$ \\
\hline Paclitaxel Niosome & $5.16 \pm 1.36$ \\
\hline Paclitaxel Niosome + Curcumin Niosome & $2.312 \pm 0.27$ \\
\hline
\end{tabular}

Figure 2 Inhibition of cell growth by curcumin and paclitaxel individual as a drug free form and drug nanoniosomal form in OVCAR-3 cell. a Free Cur vs Free PCL; b; NioCur vs NioPCL

Table 2

Curcumin and Paclitaxel Combination Index (Cl) against OVCAR-3

\begin{tabular}{|lll|}
\hline Combination type & Cl & interaction type \\
\hline Free paclitaxel + free curcumin solution & 0.27 & synergistic \\
\hline Curcumin niosome + Paclitaxel niosome & 0.35 & synergistic \\
\hline $\mathrm{Cl}<1$, synergistic; $\mathrm{Cl}=1$, additive; $\mathrm{Cl}>1$, antagonistic. & & \\
\hline $\begin{array}{l}\text { Figure } 3 \text { Analysis of synergy between curcumin and paclitaxel for OVCAR-3. a, Dose-response curve } \\
\text { of free Cur + Free PCL; } \text {; dose-response curve of NioCur + NioPCL. Cl values at different levels of } \\
\text { growth inhibition effect (fraction affected, FA; c Free Cur + Free PCL ; d NioCur + NioPCL in OVCAR-3 } \\
\text { cell) }\end{array}$ & \\
\hline
\end{tabular}

\subsection{Nanocarrier Uptake Studies}

Using the fluorescence microscopy, we examined the cellular uptake of OVCAR-3 cell, incubated with DILNioPCL and DIL-NioCur. Fig. 4a, b illustrates that the efficient entry of nanoniosome formulations into the cancerous cells, which is principally into the nucleus. It seems that the endocytosis has a vital role in cell perpetration of the drug-loaded niosomes.

Figure.4 Cellular uptake of drugs-loaded niosome on OVCAR-3 line. [A1: Niosomal Cur: Nucleus, A2: Niosomal Cur, A3: Niosomal Cur: Merged; B1: Niosomal PCL: Nucleus, B2: Niosomal PCL, B3: Niosomal PCL: Merged. 
3.4 Combination of Cur and PCL caused an increase in apoptosis than individual treatments, particularly when administered in drug niosomal form

Investigation of apoptosis was done in OVCAR-3 cell incubated with PCL and Cur, as combined PCL + Cur or as single agents, administered in nano-niosome formulations or aqueous solution (Fig. 5). The early apoptosis rate was 8.96 and $6.78 \%$ in cells treated with the free PCL and free Cur. Nevertheless, this rate showed an increase to 28.8 and $13.8 \%$ after cell treatment with NioPCL and NioCur. Moreover, there was an increase in apoptosis by combined PCL and Cur in comparison with individual treatments, particularly when used in drug niosomal form (that is, $17.7 \%$ early apoptosis in free PCL + free Cur solution vs. 49.4 $\%$ early apoptosis in PCL niosome + Cur niosome, $p<0.05)$. There is consistency between these results and the results of cytotoxicity assay (MTT approach) of Cur combined with PCL.

Figure 5 Cell apoptosis analyzed with Annexin V-FITC kit following the treatment of cells with Cur and $\mathrm{PCL}$, either as single agents or as a Cur + PCL combination, administered in aqueous solution or in nanoniosome formulations. A: Control; B: Free Curcumin; C: Free Paclitaxel; D: Free Curcumin + Free Paclitaxel; E: Niosomal Curcumin; F: Niosomal Paclitaxel; G: Niosomal Curcumin + Niosomal Paclitaxel.

3.5 Combined treatment of Cur and PCL caused a reduction in expression of Akt-1 gene more than individual treatments with either PCL or Cur, particularly when administered in drug niosomal form

With performing the real-time PCR analysis, the synergistic impact of PCL and Cur on expression of Akt-1 gene was investigated. According to results of qPCR (Fig. 6), with treating OVCAR-3 cells with free PCL solution and free Cur solution, it was observed that there is downregulation of expression of $A k t-1$ gene in comparison with untreated cells (A 51.89 and $48.07 \%$ reduction in comparison with control group). Besides, with treatment of cells with NioPCL and NioCur, an enhancement was noticed in the Akt-1 gene expression downregulation by 85.15 and $81.26 \%$. Additionally, combined treatment with PCL and Cur in both niosomal forms and free forms showed higher efficacy in reduction of expression of Akt-1 gene compared to individually administered drugs $\left.{ }^{\star \star \star \star} p<0.0001\right)$.

Besides, it was observed that the combined treatment caused a significant efficacy ( ${ }^{\star \star \star} p$-value $=0.0003$ ) in cases that PCL and Cur were administered in nanoniosome formulations than free drug solution (72.89\% reduction in free PCL + free Cur solution compared to $91 \%$ reduction in PCL niosome + Cur niosome), which shows a consistency with cytotoxicity experiments.

Figure 6. qPCR analysis of Akt-1 gene expression in OVCAR-3 cells following treatment with paclitaxel and curcumin either as a single agent or in combination, when administered in aqueous solution and nanoniosome formulations. * $\mathrm{P}<0.0001$ vs control. a: free Cur vs Free Cur + Free $P C L(P<0.0001)$ b: Free Cur vs NioCur $(P<0.0001)$. c: Free $P C L$ vs Free Cur + Free $P C L(P<0.0001)$. d: Free $P C L$ vs NioPCL $(P<$ 0.0001). e: Free Cur + Free PCL vs NioCur + NioPCL $(P=0.0003)$

3.6 Combined therapy with Cur and PCL reduced activity of NF-KB more than single therapies with either PCL or Cur, particularly when used in drug niosomal form 
ELISA assay was used for investigating the synergistic impact of Cur and PCL on activity of p65-NF-kB with analysis of the DNA binding activity of NF-KB. As indicated by the results (Fig. 7), NF-KB activity in OVCAR-3 cell was decreased due to prevention of NF-KB activation and its translocation to the nucleus by free PLC and free Cur compared with the control (a 20.20 and $36.86 \%$ reduction compared with the control). Furthermore, with treating the cells with NioPCL and NioCur, the reduced activity of NF-kB was improved to 52.55 and 58.82 percent. Moreover, combined treatment with PCL in both niosomal and free forms has shown higher efficacy in decreasing NF-KB activities compared with any drug individually ( $p<$ 0.05). Additionally, the combined treatment approach showed a significant effectiveness $(p<0.05)$ in cases that PCL and Cur were transferred in nanoniosome formulations rather than as free drug solution (a $56.47 \%$ reduction in free PCL + free Cur solution in comparison to $79.61 \%$ reduction in PCL niosome + Cur niosome). These findings show consistency with cytotoxicity experiments and results of qPCR analysis for expression of Akt-1 gene.

Figure 7. p65-NF-KB activity in OVCAR-3 cells following treatment with paclitaxel and curcumin either as a single agent or in combination, when administered in aqueous solution and nanoniosome formulations. *P < 0.05 vs control. a: free Cur vs Free Cur + Free $P C L(P<0.05)$. b: Free Cur vs NioCur $(P<0.05)$. c: Free PCL vs Free Cur + Free PCL( $=0.0002)$. d: Free PCL vs Nio PCL $(P=0.0005)$. e: Free Cur + Free PCL vs NioCur + NioPCL $(P<0.05)$.

\section{Discussion}

Different types of cancer are commonly treated with Chemotherapy as a standard therapy. However, it is accompanied by low therapeutic efficacy and high systemic toxicity (39). Combined chemotherapy is a promising approach for generating synergistic antitumor impact. An attractive anticancer approach is combining PCL and Cur (8). Although Cur and PCL represent satisfactory therapeutic impacts, their water solubility is poor. Accordingly, demands for effective strategies for delivery of PCL and Cur have led to attractive systems for formulations of PCL and Cur, like polymeric micelles, polymeric nanoparticles, liposomes, nanogels, biodegradable microspheres, cyclodextrin, and niosomes (11-14). In the present work, Cur and PCL we're loaded into nanoniosome formulations in order to enhance effectiveness in OVCAR-3 human ovarian cancer cell. Our results showed high efficiency of nanoniosomes in delivery of Cur and PCL drugs to OVCAR-3 cell (Table 1). Concentration of PCL and Cur was reduced by 3.8 and 2.8 fold, when administering the PCL and Cur in nanoniosomes in comparison with free PCL and free Cur and solutions in OVCAR-3 cell. A combination study was carried out for determining the synergistic antitumor impact of Cur and PCL. As a result of combined treatment with PCL and cur, cell viability reduction was more in OVCAR-3 compared to either Cur or PCL individually. In delivering the PCLand Cur in nanoniosome formulations compared to a free solution, such a combined treatment approach was effective ( $p$ value < 0.05) (Table 2). Therefore, when the PCL and Cur are used together, the therapeutic potential is enhanced. Our results showed the ability of Cur for increasing the cell growth inhibition of PCL so that when free Cur was present, the $I_{50}$ of free PCL was decreased to about $1.4-$ fold. $_{\text {. The IC }} \mathrm{I}_{50}$ of NioPCL was decreased to about 2.2 -fold with presence of NioCur. It was indicated that Cur, lonely or 
combined with other compounds, has an anticancer function by regulation of multiple signaling pathways, such as p53 signaling pathway, the apoptotic-signaling cascade, the Wnt/ $\beta$-catenin signaling pathway, NF-KB pathway, JAK/ STAT signaling pathway, the AKT pathway, and AMPK/COX-2 pathway (40-43). The phosphoinositide 3-kinase (PI3K)/Akt signaling pathway is significant for many cellular functions, including control of growth, cell survival, cell proliferation, and metabolism. There is a high expression of AKT in breast cancer carcinogenesis because of its capacity for regulating cell growth, cycle, apoptosis, and proliferation $(41,44)$. We evaluated relative expression of AKT-1 gene in OVCAR-3 cells following treatment with free Cur, free PCL, free Cur + free PCL, NioCur, NioPCL and NioCur + NioPCL. As demonstrated by the results, expression of AKT-1 gene was reduced in OVCAR-3 cancerous cells by both free Cur and free PCL. Furthermore, a 85.15 and $81.26 \%$ reduction was observed in expression of AKT-1 gene when administration of free PCL and free Cur in niosomal formulations that was significantly lower than the free forms $(P<0.05)$. Also, it was indicated that co-administering Cur and PCL nanoniosome formulations reduced expression of $A K T-1$ gene by $91 \%$, which shows higher efficacy compared to combined treatment of free drugs. Cur has the capability of down-regulation of NF-KB pathways. NF-KB pathway has responsibility of tumor cell survival anda metastasis. NF-KB is a transcription factor that is available in the cytoplasm as an inactive heterotrimer composed of p65, p50, and $І \kappa B a$ subunits. IKBa subunit is phosphorylated and degraded by IKB kinase (IKK) in response to specific stimuli. Thus, NF-KB is translocated into the nucleus, and the transcription of some genes is initiated. These genes are responsible for survival and metastasis of tumor cell. IKK is inhibited by Cur, and hence, the IKBa degradation is prevented. As long as IKBa is not degraded, NF-KB stays in the inactive state, resulting in improved apoptosis in tumor cells. Accordingly, it is possible to use Cur as an efficient sensitizer for increasing therapeutic reaction of cancerous cells to common chemotherapeutic medicines $(9,45)$. The present research findings showed significant reduction of NF-KB activation by both Cur and PCL. Moreover, with administering free PCL and free Cur in nanoniosomal formulations, 52.55 and $58.82 \%$ reduction was observed in NF-KB activation, which was significantly lower compared to the free forms $(P<0.05)$. Also, it seems that nanoniosomal formulations has a role in improving activity through drugs' effective internalization. In comparison with combined treatment with Cur and PCL in aqueous solution, combined treatment with Cur and PCL in nanoniosomes showed higher efficiency in reducing activation of NF-KB (a $56.47 \%$ reduction in free PCL + free Cur solution in comparison with $79.61 \%$ reduction in PCL niosome + Cur niosome). Cell apoptosis is described as an autonomous cell death process that can be caused by various chemical and physical factors and different drugs. It has been described that apoptosis induction is the best and an standard strategy in anti-cancer therapy. Apoptosis is promoted by Cur as a natural polyphenolic complex, which is accomplished through interference in different cell survival signaling pathways, like Akt and NF-KB $(46,47)$.

In the present work, it was found that both Cur and PCL had a significant role in increasing apoptosis. Nevertheless, an increase was observed in the rate of early apoptosis to 28.8 and $13.8 \%$ after treatment of cells with NioPCL and NioCur. Besides, the combined administration of PCL and Cur increased apoptosis in comparison with individual therapies, particularly when applied in drug niosomal form (that 
is, $\mathbf{1 7 . 7} \%$ early apoptosis in free PCL + free Cur solution vs. $49.4 \%$ early apoptosis in PCL niosome + Cur niosome, $p<0.05)$.

\section{Conclusion}

A nonionic surfactant vesicle of Cur and PTX was successfully developed in the present work, and it was characterized regarding size, loading efficiency, and in vitro drug release. The encapsulation efficiency of the drugs was high. As demonstrated by the release profile of the drugs, burst release was followed by a constant drug release for both agents. When Cur (an efficient chemosensitizer) and PCL (a robust anticancer drug) are used in a combined way, especially in nanoniosome formulations, the therapeutic efficacy of Cur and PCL can be increased in reducing AKT-1 gene expression, reducing activation of NF-KB, and enhancing apoptosis. Considerable potential can be achieved in the cancer clinical management using this dual therapeutic strategy, particularly based on nonionic surfactant vesicles.

\section{Declarations}

Ethics approval and consent to participate: The manuscript was approved by the Abadan University of Medical Sciences Internal Review Board. There are no human subjects or animals involved in the study.

Consent for publication: Not applicable

Availability of data and materials: All data generated or analyzed during this study are included in this article.

Competing interests: The authors declare that they have no competing interests.

Funding: This study was financially supported by grant from the Abadan University of Medical Sciences, Abadan, Iran.

Authors' contributions: All authors had equal role in design, work, statistical analysis and manuscript writing.

Acknowledgements: Not applicable.

\section{Authors' Affiliations}

(1) Abadan University of Medical Sciences, Abadan, Iran

(2) Shoushtar Faculty of Medical Sciences, Shoushtar, Iran

(3) Nutrition and Metabolic Diseases Research Center, Ahvaz Jundishapur University of Medical Sciences, Ahvaz, Iran

(4) Department of Pediatrics, Sabzevar University of Medical Sciences, Sabzevar, Iran 
(5) Department of Medical Sciences, Shahrood Branch, Islamic Azad University, Shahrood, Iran

(6) Student Research Committee, Shiraz University of Medical Sciences, Shiraz, Iran

(7) Hematology and oncology research center, Shahid Sadoughi University of Medical Sciences, Yazd, Iran

(8) Kar Higher Education Institute of Rafsanjan, Rafsanjan, Iran

\section{References}

1. Huang P, Wang D, Su Y, Huang W, Zhou Y, Cui D, et al. Combination of Small Molecule Prodrug and Nanodrug Delivery: Amphiphilic Drug-Drug Conjugate for Cancer Therapy. Journal of the American Chemical Society. 2014;136(33):11748-56.

2. Zhang Y, Yang C, Wang W, Liu J, Liu Q, Huang F, et al. Co-delivery of doxorubicin and curcumin by pH-sensitive prodrug nanoparticle for combination therapy of cancer. Scientific reports. 2016;6:21225.

3. Zou P, Song J, Jiang B, Pei F, Chen B, Yang X, et al. Epigallocatechin-3-gallate protects against cisplatin nephrotoxicity by inhibiting the apoptosis in mouse. International Journal of Clinical and Experimental Pathology. 2014;7(8):4607-16.

4. Greco F, Vicent MJ. Combination therapy: opportunities and challenges for polymer-drug conjugates as anticancer nanomedicines. Advanced drug delivery reviews. 2009;61(13):1203-13.

5. Parhi P, Mohanty C, Sahoo SK. Nanotechnology-based combinational drug delivery: an emerging approach for cancer therapy. Drug discovery today. 2012;17(17-18):1044-52.

6. Wang H, Zhao Y, Wu Y, Hu YL, Nan K, Nie G, et al. Enhanced anti-tumor efficacy by co-delivery of doxorubicin and paclitaxel with amphiphilic methoxy PEG-PLGA copolymer nanoparticles. Biomaterials. 2011;32(32):8281-90.

7. Wang W, Xi M, Duan X, Wang Y, Kong F. Delivery of baicalein and paclitaxel using self-assembled nanoparticles: synergistic antitumor effect in vitro and in vivo. International journal of nanomedicine. 2015;10:3737-50.

8. Muthoosamy K, Abubakar IB, Bai RG, Loh HS, Manickam S. Exceedingly Higher co-loading of Curcumin and Paclitaxel onto Polymer-functionalized Reduced Graphene Oxide for Highly Potent Synergistic Anticancer Treatment. Scientific reports. 2016;6:32808.

9. Wang J, Wang F, Li F, Zhang W, Shen Y, Zhou D, et al. A multifunctional poly(curcumin) nanomedicine for dual-modal targeted delivery, intracellular responsive release, dual-drug treatment and imaging of multidrug resistant cancer cells tElectronic supplementary information (ESI) available: The synthesis procedure of Biotin-PEG-PCDA and the experimental results of MTT. See DOI: 
10.1039/c5tb02450a Click here for additional data file. Journal of Materials Chemistry B, Materials for Biology and Medicine. 2016;4(17):2954-62.

10. Baek JS, Cho CW. A multifunctional lipid nanoparticle for co-delivery of paclitaxel and curcumin for targeted delivery and enhanced cytotoxicity in multidrug resistant breast cancer cells. Oncotarget. 2017;8(18):30369-82.

11. Naksuriya O, Okonogi S, Schiffelers RM, Hennink WE. Curcumin nanoformulations: a review of pharmaceutical properties and preclinical studies and clinical data related to cancer treatment. Biomaterials. 2014;35(10):3365-83.

12. Yallapu MM, Jaggi M, Chauhan SC. Curcumin nanoformulations: a future nanomedicine for cancer. Drug Discovery Today. 2012;17(1-2):71-80.

13. Yallapu MM, Nagesh PK, Jaggi M, Chauhan SC. Therapeutic Applications of Curcumin Nanoformulations. The AAPS journal. 2015;17(6):1341-56.

14. Yang X, Li Z, Wang N, Li L, Song L, He T, et al. Curcumin-Encapsulated Polymeric Micelles Suppress the Development of Colon Cancer In Vitro and In Vivo. Scientific Reports. 2015;5:10322.

15. Bagheri A, Seang Chu, B , Yaakob,H. Niosomal Drug Delivery Systems: Formulation, Preparation and Applications. World Applied Sciences Journal 2014;32(8):1671-85.

16. Marianecci C, Di Marzio L, Rinaldi F, Celia C, Paolino D, Alhaique F, et al. Niosomes from 80s to present: The state of the art. Advances in Colloid and Interface Science. 2014;205:187-206.

17. Mohamed HB, El-Shanawany SM, Hamad MA, Elsabahy M. Niosomes: A Strategy toward Prevention of Clinically Significant Drug Incompatibilities. Scientific Reports. 2017;7(1):6340.

18. Ojeda E, Puras G, Agirre M, Zarate J, Grijalvo S, Pons R, et al. Niosomes based on synthetic cationic lipids for gene delivery: the influence of polar head-groups on the transfection efficiency in HEK293, ARPE-19 and MSC-D1 cells. Organic \& Biomolecular Chemistry. 2015;13(4):1068-81.

19. Uchegbu IF, Vyas SP. Non-ionic surfactant based vesicles (niosomes) in drug delivery. International Journal of Pharmaceutics. 1998;172(1):33-70.

20. Alemi A, Zavar Reza J, Haghiralsadat F, Zarei Jaliani H, Haghi Karamallah M, Hosseini SA, et al. Paclitaxel and curcumin coadministration in novel cationic PEGylated niosomal formulations exhibit enhanced synergistic antitumor efficacy. Journal of Nanobiotechnology. 2018;16(1):28.

21. Alemi A F, M., Haghi Karamallah, M., Farrokhifar, M., Entezari Nasab, Z., Farrokhifar,. A A novel Paclitaxel loaded Noisome: Preparation, Characterization and Cytotoxicity Assessment against human prostate cancer. Cancer Press. 2017;3(3):103-12. 
22. Alemi A F, M., Haghi Karamallah, M., Farrokhifar, M., Entezari Nasab, Z., Farrokhifar, A. Evaluation of the efficacy of Niosomal Curcumin Nanoformulation in Cancer therapy. Cancer Press. 2017;3((3):):7785 .

23. Sharma V, Anandhakumar S, Sasidharan M. Self-degrading niosomes for encapsulation of hydrophilic and hydrophobic drugs: An efficient carrier for cancer multi-drug delivery. Materials Science and Engineering: C. 2015;56:393-400.

24. Alemi A, Farrokhifar M, Zare-Zardini H, Haghi Karamallah M. A Comparison between the Anticancer Activities of Free Paclitaxel and Paclitaxel-Loaded Niosome Nanoparticles on Human Acute Lymphoblastic Leukemia Cell Line Nalm-6. Iranian journal of Pediatric Hematology and Oncology. 2018;8(3):153-60.

25. Kassem MA, El-Sawy HS, Abd-Allah Fl, Abdelghany TM, El-Say KM. Maximizing the Therapeutic Efficacy of Imatinib Mesylate-Loaded Niosomes on Human Colon Adenocarcinoma Using Box-Behnken Design. Journal of pharmaceutical sciences. 2017;106(1):111-22.

26. Shaker DS, Shaker MA, Hanafy MS. Cellular uptake, cytotoxicity and in-vivo evaluation of Tamoxifen citrate loaded niosomes. International Journal of Pharmaceutics. 2015;493(1):285-94.

27. Tavano L, Muzzalupo R, Picci N, de Cindio B. Co-encapsulation of antioxidants into niosomal carriers: Gastrointestinal release studies for nutraceutical applications. Colloids and Surfaces B: Biointerfaces. 2014;114:82-8.

28. Zare-Zardini H, Alemi A, Taheri-Kafrani A, Hosseini SA, Soltaninejad H, Hamidieh AA, et al. Assessment of a New Ginsenoside Rh2 Nanoniosomal Formulation for Enhanced Antitumor Efficacy on Prostate Cancer: An in vitro Study. Drug Des Devel Ther. 2020;14:3315-24.

29. El-Hamid ESA, Gamal-Eldeen AM, Sharaf Eldeen AM. Liposome-coated nano doxorubicin induces apoptosis on oral squamous cell carcinoma CAL-27 cells. Archives of Oral Biology. 2019;103:47-54.

30. Gumulec J, Fojtu M, Raudenska M, Sztalmachova M, Skotakova A, Vlachova J, et al. Modulation of induced cytotoxicity of doxorubicin by using apoferritin and liposomal cages. Int J Mol Sci. 2014;15(12):22960-77.

31. Zhu C, He L, Zhou X, Nie X, Gu Y. Sulfatase 2 promotes breast cancer progression through regulating some tumor-related factors. Oncol Rep. 2016;35(3):1318-28.

32. Asoodeh A, Alemi A, Heydari A, Akbari J. Purification and biochemical characterization of an acidophilic amylase from a newly isolated Bacillus sp. DR90. Extremophiles : life under extreme conditions. 2013;17(2):339-48.

33. Ramakers C, Ruijter JM, Deprez RHL, Moorman AFM. Assumption-free analysis of quantitative real-time polymerase chain reaction (PCR) data. Neuroscience Letters. 2003;339(1):62-6. 
34. Ruijter JM, Lefever S, Anckaert J, Hellemans J, Pfaffl MW, Benes V, et al. RDML-Ninja and RDMLdb for standardized exchange of qPCR data. BMC bioinformatics. 2015;16:197.

35. Ruijter JM, Ramakers C, Hoogaars WM, Karlen Y, Bakker O, van den Hoff MJ, et al. Amplification efficiency: linking baseline and bias in the analysis of quantitative PCR data. Nucleic acids research. 2009;37(6):e45.

36. De Pascale C, Graham V, Fowkes RC, Wheeler-Jones CP, Botham KM. Suppression of nuclear factor-kappaB activity in macrophages by chylomicron remnants: modulation by the fatty acid composition of the particles. The FEBS journal. 2009;276(19):5689-702.

37. Malaponte G, Signorelli SS, Bevelacqua V, Polesel J, Taborelli M, Guarneri C, et al. Increased Levels of NF-kB-Dependent Markers in Cancer-Associated Deep Venous Thrombosis. PloS one. 2015;10(7):e0132496.

38. Saha D, Koli S, Patgaonkar M, Reddy KV. Expression of hemoglobin-alpha and beta subunits in human vaginal epithelial cells and their functional significance. PloS one. 2017;12(2):e0171084.

39. Ruttala HB, Ko YT. Liposomal co-delivery of curcumin and albumin/paclitaxel nanoparticle for enhanced synergistic antitumor efficacy. Colloids and Surfaces B: Biointerfaces. 2015;128:419-26.

40. Devassy JG, Nwachukwu ID, Jones PJH. Curcumin and cancer: barriers to obtaining a health claim. Nutrition Reviews. 2015;73(3):155-65.

41. Guan F, Ding Y, Zhang Y, Zhou Y, Li M, Wang C. Curcumin Suppresses Proliferation and Migration of MDA-MB-231 Breast Cancer Cells through Autophagy-Dependent Akt Degradation. PloS one. 2016;11(1):e0146553.

42. Liu D, Chen Z. The Effect of Curcumin on Breast Cancer Cells. J Breast Cancer. 2013;16(2):133-7.

43. Shehzad A, Lee YS. Molecular mechanisms of curcumin action: Signal transduction. BioFactors. 2013;39(1):27-36.

44. Seo BR, Min KJ, Cho IJ, Kim SC, Kwon TK. Curcumin significantly enhances dual PI3K/Akt and mTOR inhibitor NVP-BEZ235-induced apoptosis in human renal carcinoma Caki cells through downregulation of p53-dependent $\mathrm{Bcl}-2$ expression and inhibition of $\mathrm{Mcl}-1$ protein stability. PloS one. 2014;9(4):e95588.

45. Ganta S, Amiji M. Coadministration of Paclitaxel and curcumin in nanoemulsion formulations to overcome multidrug resistance in tumor cells. Molecular pharmaceutics. 2009;6(3):928-39.

46. Bava SV, Sreekanth CN, Thulasidasan AKT, Anto NP, Cheriyan VT, Puliyappadamba VT, et al. Akt is upstream and MAPKs are downstream of NF-KB in paclitaxel-induced survival signaling events, which 
are down-regulated by curcumin contributing to their synergism. The International Journal of Biochemistry \& Cell Biology. 2011;43(3):331-41.

47. Liu T-Y, Tan Z-J, Jiang L, Gu J-F, Wu X-S, Cao Y, et al. Curcumin induces apoptosis in gallbladder carcinoma cell line GBC-SD cells. Cancer Cell Int. 2013;13(1):64-.

\section{Figures}

\section{In vitro Release Curve}

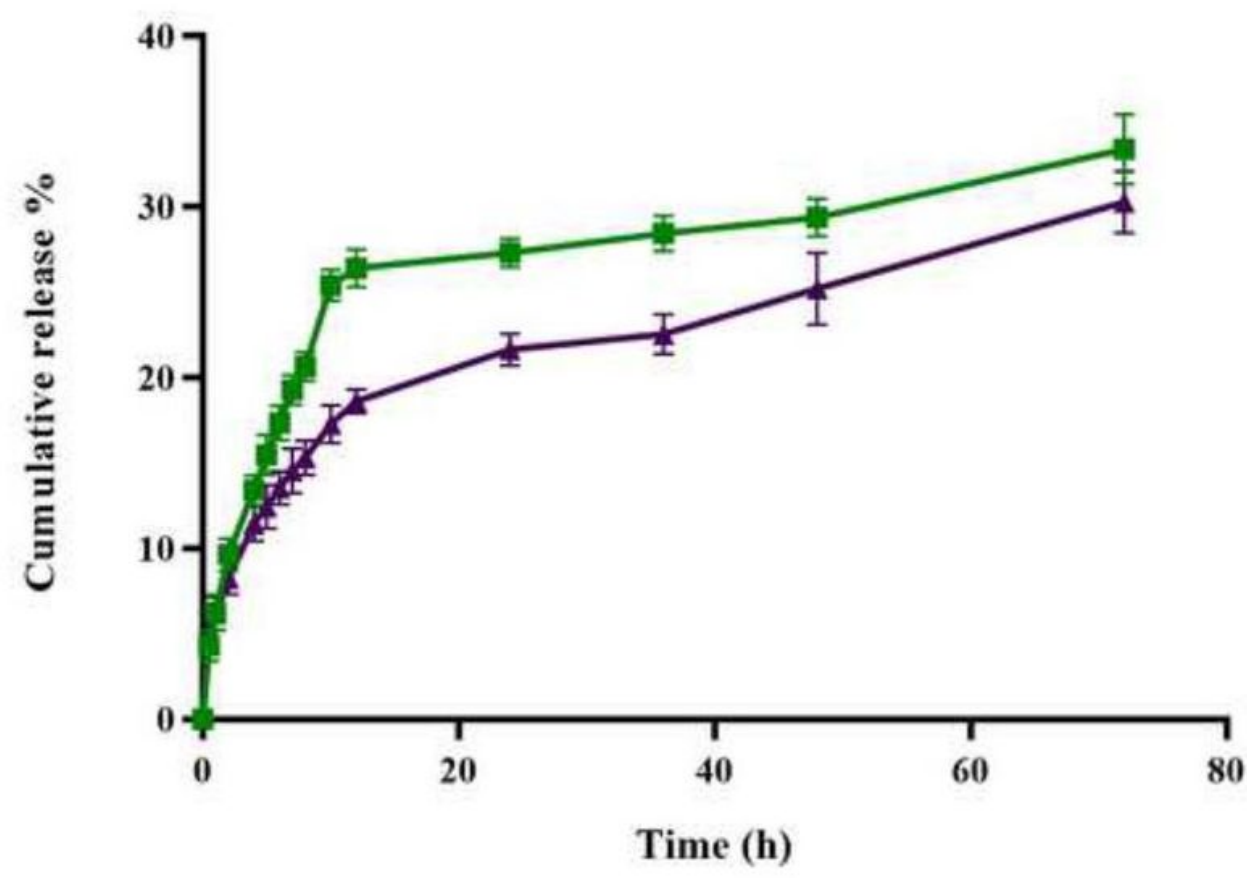

\section{Figure 1}

The in vitro release profile of curcumin and paclitaxel from niosome formula. 

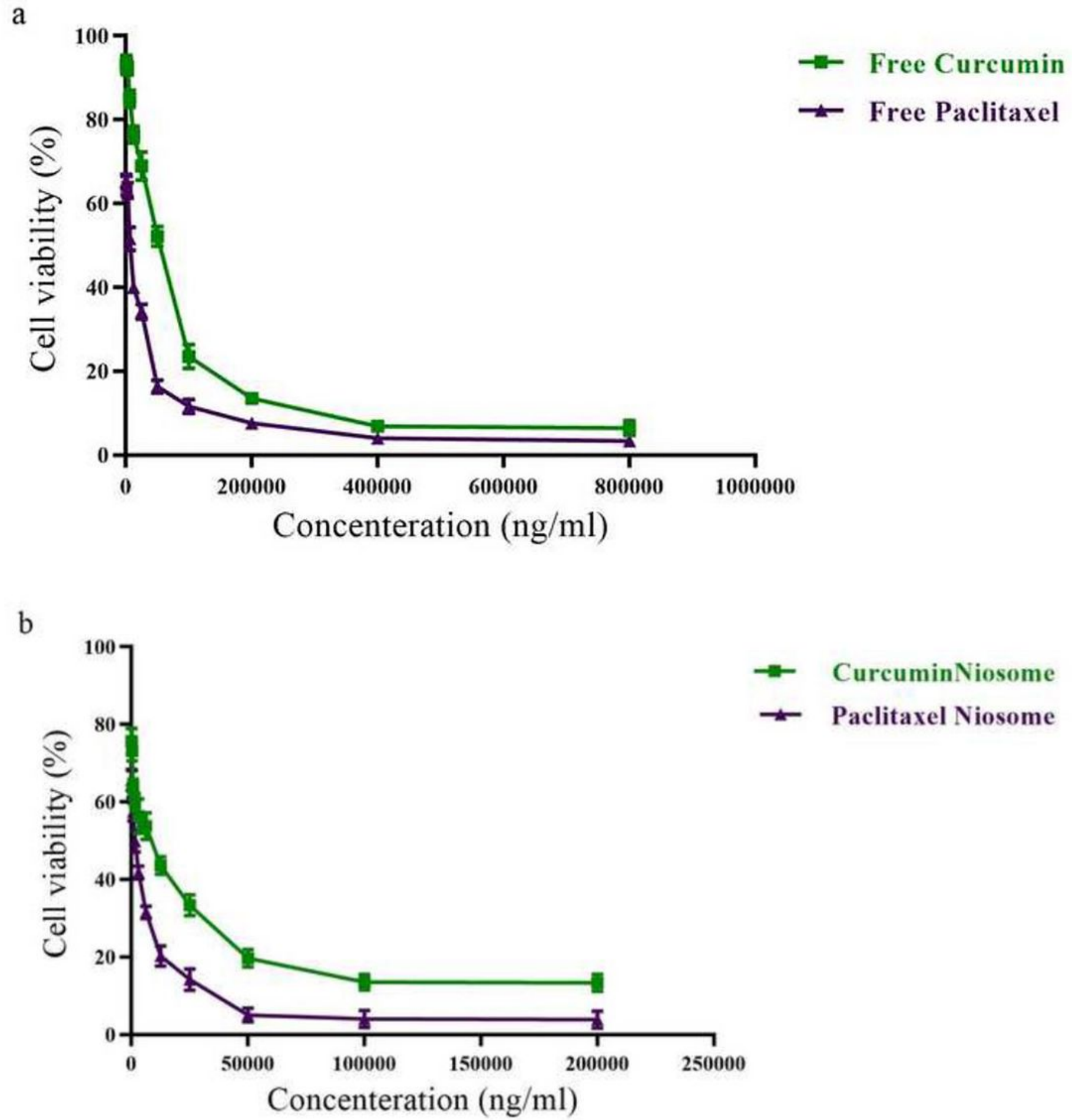

Figure 2

Inhibition of cell growth by curcumin and paclitaxel individual as a drug free form and drug nanoniosomal form in OVCAR-3 cell. a Free Cur vs Free PCL; b; NioCur vs NioPCL 
a

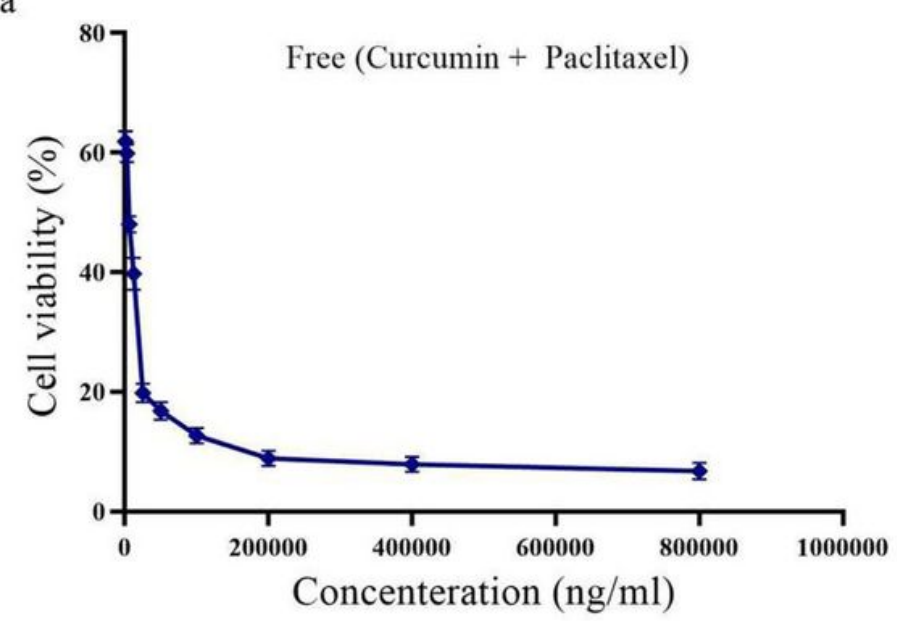

c

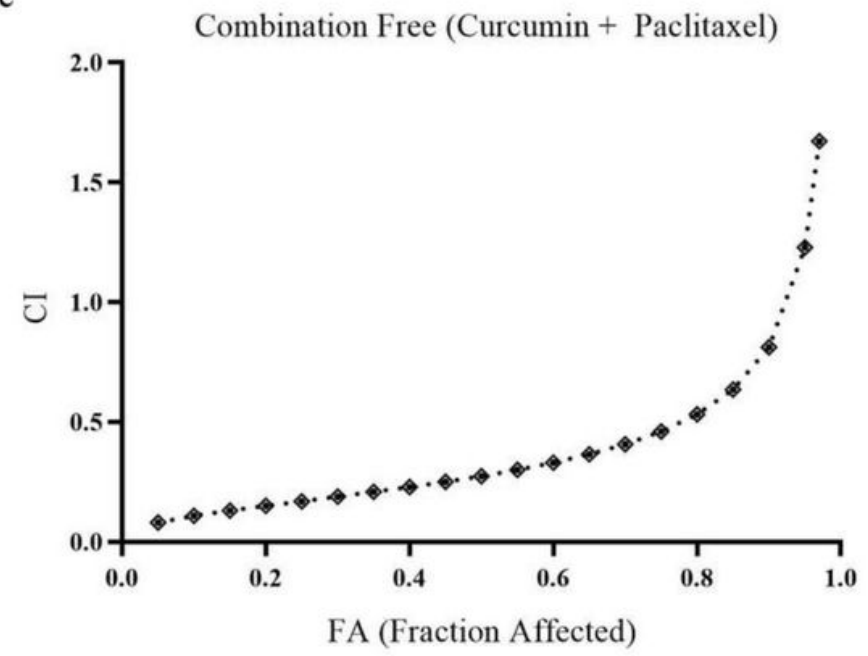

$\mathrm{b}$

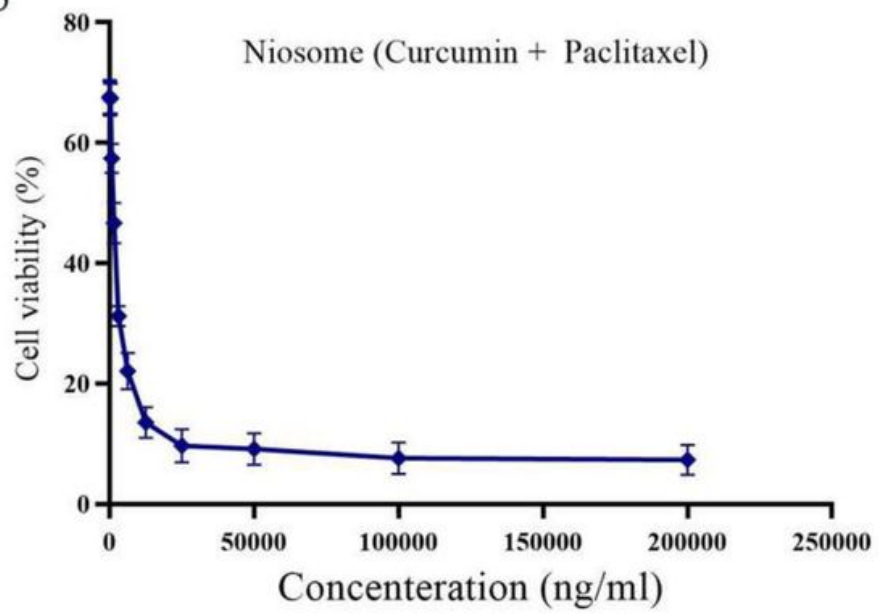

d

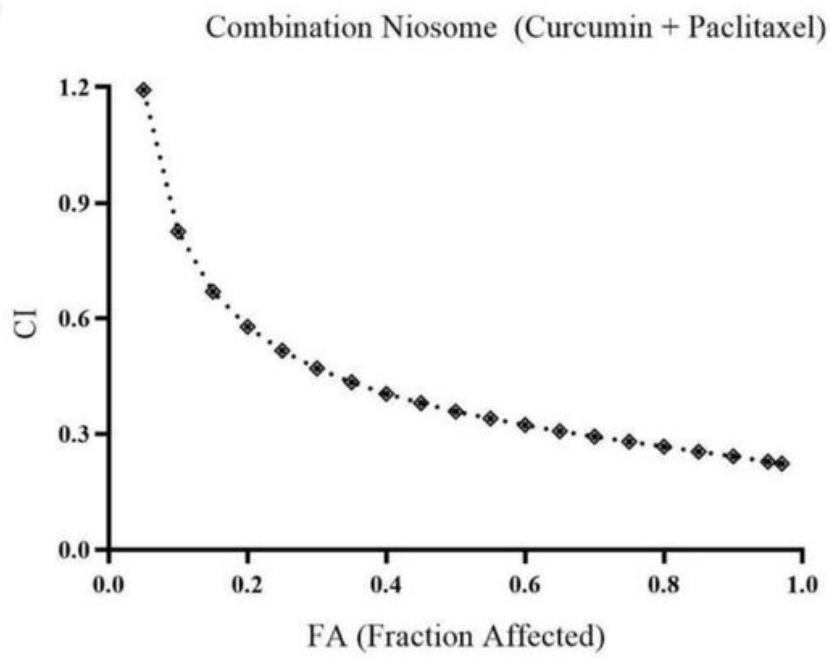

\section{Figure 3}

Analysis of synergy between curcumin and paclitaxel for OVCAR-3. a, Dose-response curve of free Cur + Free PCL ; $b$ dose-response curve of NioCur + NioPCL. Cl values at different levels of growth inhibition effect (fraction affected, FA; c Free Cur + Free PCL ; d NioCur + NioPCL in OVCAR-3 cell) 

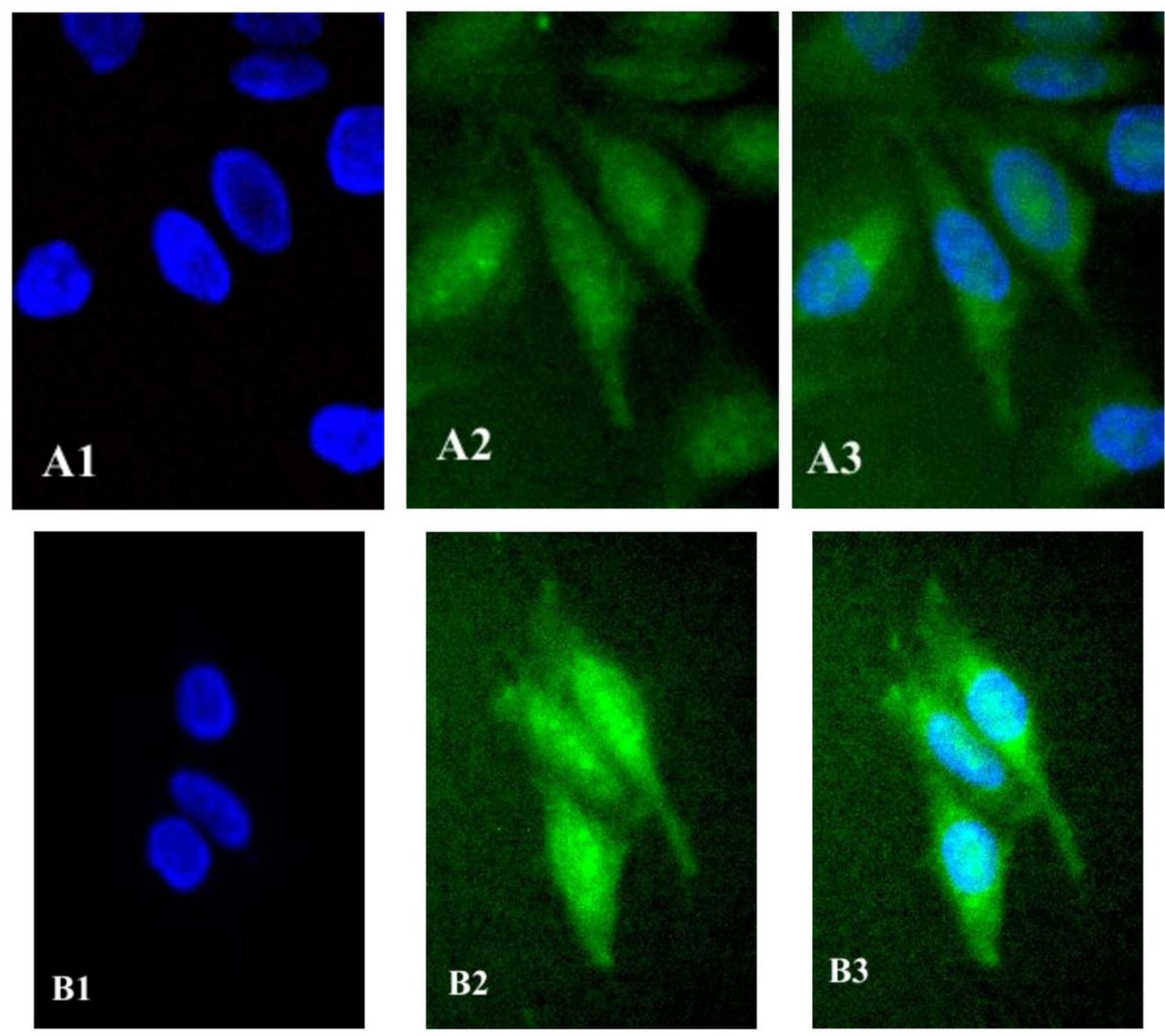

Figure 4

Cellular uptake of drugs-loaded niosome on OVCAR-3 line. [A1: Niosomal Cur: Nucleus, A2: Niosomal Cur, A3: Niosomal Cur: Merged; B1: Niosomal PCL: Nucleus, B2: Niosomal PCL, B3: Niosomal PCL: Merged. 

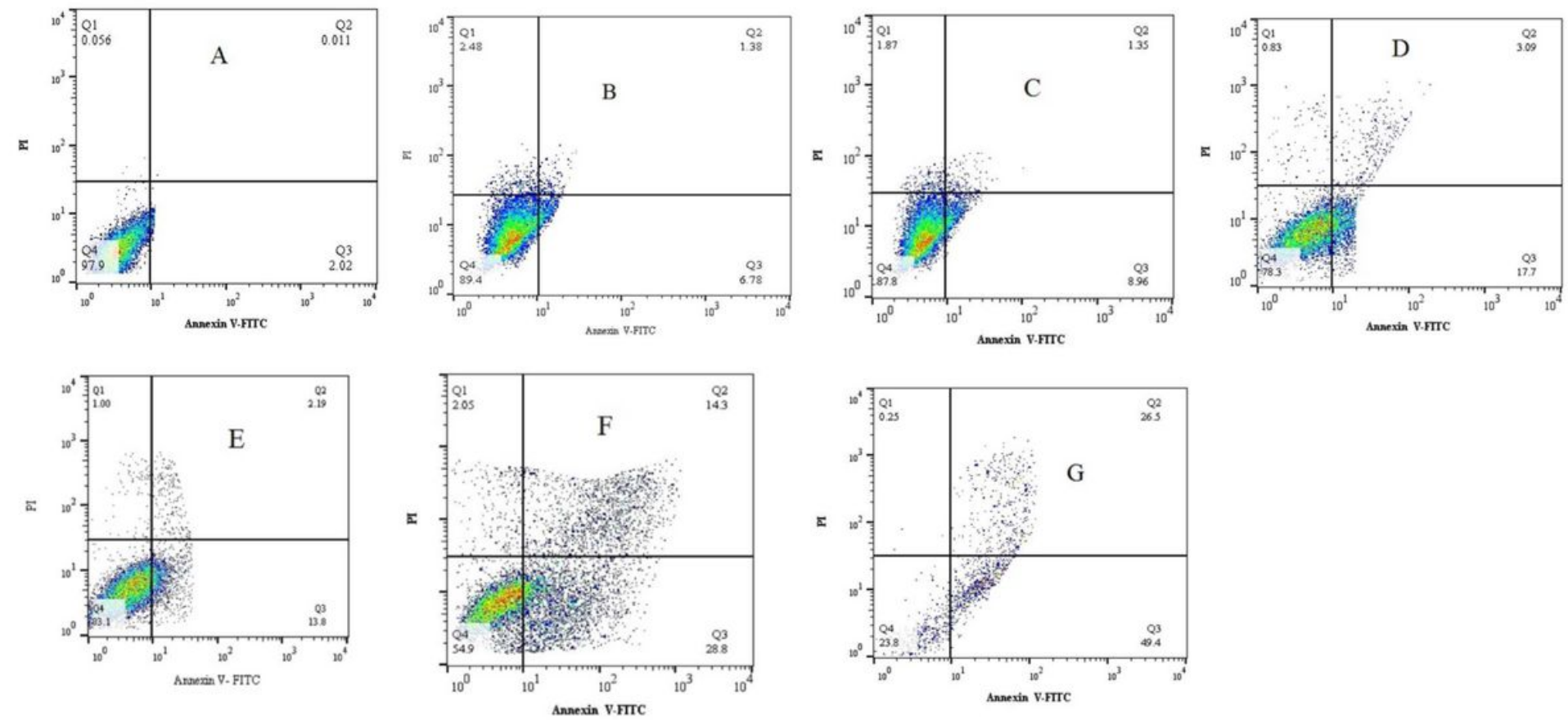

Figure 5

Cell apoptosis analyzed with Annexin V-FITC kit following the treatment of cells with Cur and PCL, either as single agents or as a Cur + PCL combination, administered in aqueous solution or in nano-niosome formulations. A: Control; B: Free Curcumin; C: Free Paclitaxel; D: Free Curcumin + Free Paclitaxel; E: Niosomal Curcumin; F: Niosomal Paclitaxel; G: Niosomal Curcumin + Niosomal Paclitaxel. 


\section{Akt-1 Gene Expression}

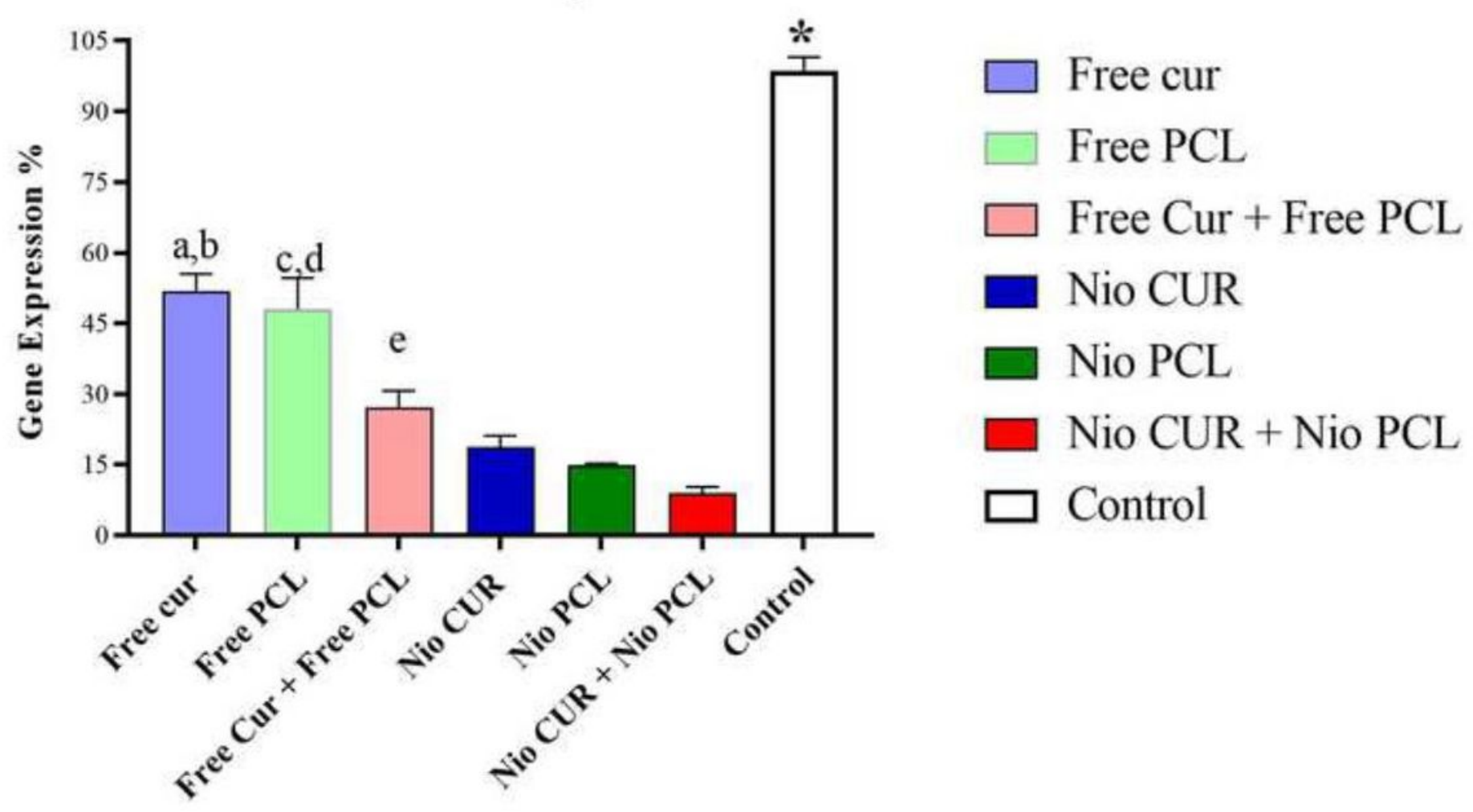

Figure 6

qPCR analysis of Akt-1 gene expression in OVCAR-3 cells following treatment with paclitaxel and curcumin either as a single agent or in combination, when administered in aqueous solution and nanoniosome formulations. ${ }^{*} P<0.0001$ vs control. a: free Cur vs Free Cur+ Free $P C L(P<0.0001)$ b: Free Cur vs NioCur $(P<0.0001)$. C: Free $P C L$ vs Free Cur+ Free $P C L(P<0.0001)$. d: Free $P C L$ vs NioPCL $(P<$ 0.0001). e: Free Cur+ Free PCL vs NioCur+ NioPCL $(P=0.0003)$ 


\section{Activity NFkB p65 subunit}

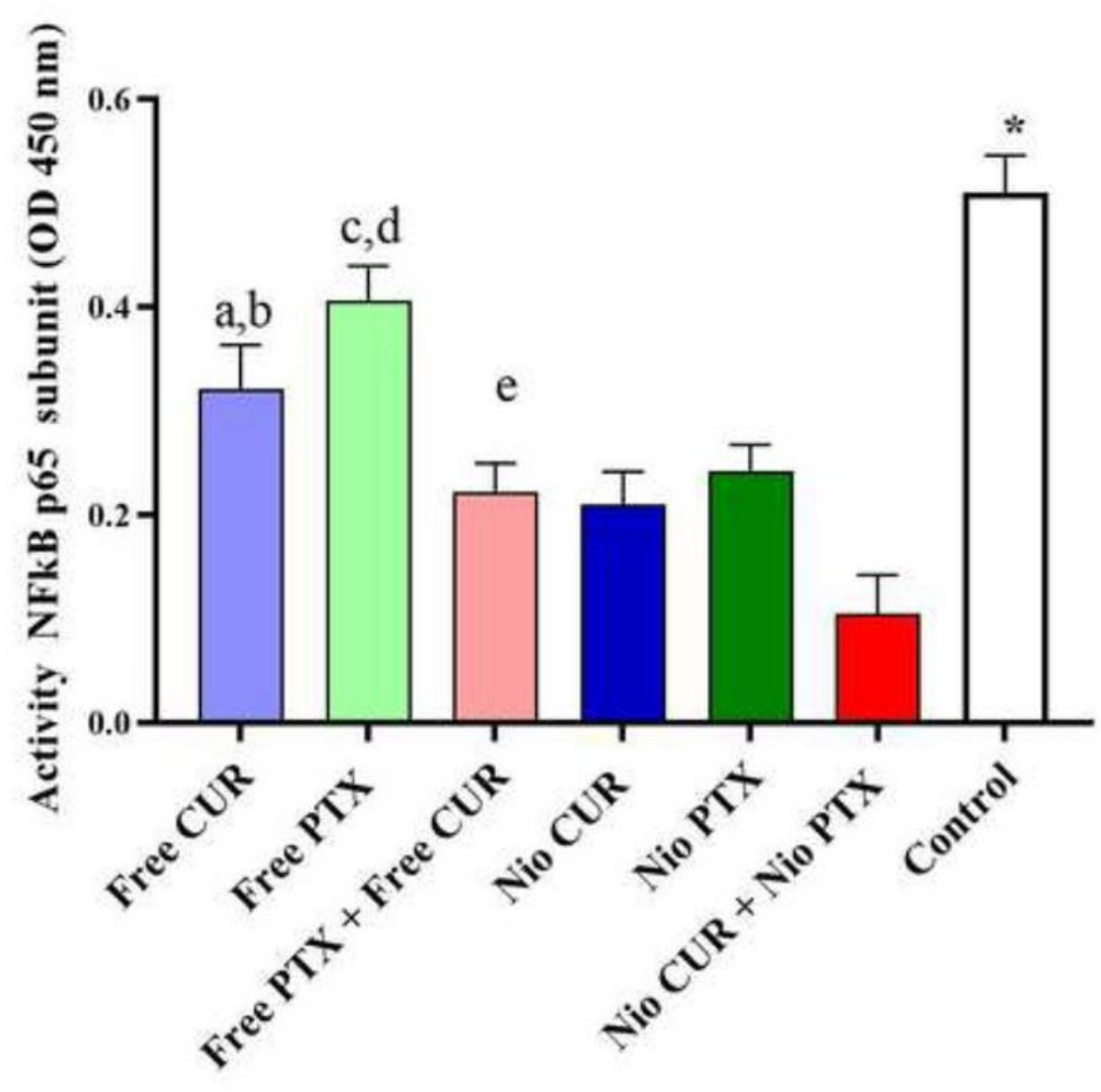

$\square$ Free CUR

$\square$ Free PTX

$\square$ Free PTX + Free CUR

- Nio CUR

Nio PTX

$\square$ Nio CUR + Nio PTX

Control

Figure 7

p65-NF-KB activity in OVCAR-3 cells following treatment with paclitaxel and curcumin either as a single agent or in combination, when administered in aqueous solution and nanoniosome formulations. ${ }^{*} \mathrm{P}<$ 0.05 vs control. a: free Cur vs Free Curt Free $P C L(P<0.05)$. b: Free Cur vs NioCur $(P<0.05)$. c: Free $P C L$ vs Free Cur+ Free $P C L(P=0.0002)$. d: Free $P C L$ vs Nio $P C L(P=0.0005)$. e: Free Cur+ Free PCL vs NioCur+ NioPCL $(P<0.05)$.

\section{Supplementary Files}

This is a list of supplementary files associated with this preprint. Click to download.

- GraphicalAbstract.png 